\title{
Pineal Region Neoplasm
}

National Cancer Institute

\section{Source}

National Cancer Institute. Pineal Region Neoplasm. NCI Thesaurus. Code C3328.

Neoplasms that are located in the pineal gland. These neoplasms arise either from pineal parenchymal cells (pineocytes), as do pineocytomas and the more aggressive pineoblastomas, or from other cell types, as do pineal astrocytic tumors (notably pilocytic astrocytomas) and germ cell tumors. Clinical symptoms include neuro-ophthalmologic dysfunction, changes in mental status, dysfunction of the brain stem, and hypothalamicbased endocrine abnormalities. 